\title{
STRUCTURAL DYNAMIC ANALYSIS OF THE CHENDEROH DAM SECTOR GATE SECTION
}

\section{Mohamad Hazwan Mohd Ghazali ${ }^{1}$, Mohd Hafiz Zawawi ${ }^{2}$, Nurul Husna Hassan ${ }^{2}$, Mohd Rashid Mohd Radzi ${ }^{2,3}$, Ahmad Zhafran Ahmad Mazlan ${ }^{1 *}$, Mohamad Aizat Abas $^{1}$ and Mohd Remy Rozainy Mohd Arif Zainol ${ }^{4}$}

\author{
${ }^{1}$ School of Mechanical Engineering, Engineering Campus, Universiti Sains Malaysia, \\ Penang \\ ${ }^{2}$ Department of Civil Engineering, College of Engineering, Universiti Tenaga Nasional, \\ Selangor \\ ${ }^{3}$ TNB Generation Division, Tenaga Nasional Berhad, Kuala Lumpur \\ ${ }^{4}$ School of Civil Engineering, Engineering Campus, Universiti Sains Malaysia, Penang \\ *Email: zhafran@usm.my
}

\begin{abstract}
The dynamic characteristics such as natural frequencies, mode shapes and frequency response function (FRF) are the important characteristics to be investigated to access the level of durability of any dam structures. These characteristics are important since it will be the reference information for any operational methods to be used for the dam structures. In this study, one of the real dam (i.e., Chenderoh Dam) that available in Malaysia is taken into consideration, where the dynamic analysis of the sector gate section of the dam structure is investigated. The real scale of the sector gate section is measured on site and modelled into the CAD software with the consideration of real build-in materials. Then, the finite element (FE) model is constructed in ANSYS software with the required boundary condition and meshing sensitivity analysis. From the result of modal analysis, 30 natural frequencies are determined in the range of $0.5904 \mathrm{~Hz}$ to $8.471 \mathrm{~Hz}$ together with the mode shapes but only the most significant natural frequencies will be shown in this paper. In addition, all three axes of the FRF graphs show an agreement for the highest natural frequency value at $7.95 \mathrm{~Hz}$, where the maximum deflection occurred in $x$ axis direction with $2.03 \times 10^{-7} \mathrm{~m}$.
\end{abstract}

Keywords: Dynamic analysis, natural frequency, mode shape, FRF, dam structure.

\section{INTRODUCTION}

Sector gate section of the dam controls the flow of water from upstream to the downstream area and considered as one of the vital parts of the dam structure. Thus, it is important to study the dynamic characteristic of the dam in order to determine the structure behavior under dynamic loading. Usually when analyzing the dam, static and dynamic properties are considered as fundamental elements where static properties are related to the design and post-construction monitoring and dynamic properties take preference in structural monitoring of dam in seismic zones [1]. Natural frequencies, mode shapes and FRF are among the critical dynamic characteristics of the dam structure. Natural frequencies can be defined as frequencies at which the structure naturally inclines to vibrate if it is subjected to disturbance whereas the behavior of the structure at a specific natural frequency of vibration are known as mode shape [2]. In addition, each mode shape is corresponding to a specific natural frequency. FRF on the 
other hand helps to determine the response of a structure at a given frequency in terms of deformation, velocity and acceleration [3]. The peak responses of FRF graph are related to the natural frequencies of the structure [4]. Better understanding on dynamic response and information regarding the dynamic characteristic of dam structure will be useful in maintaining the safety of the dam structure [5].

\section{METHODOLOGY}

\section{Initial Validation of Dam Material}

Experimental modal analysis (EMA) is carried out for the real dam concrete material and compared with the simulation of two different concrete materials in order to validate the natural frequencies of the materials before running the simulation for the sector gate section. LMS TestLab, impact hammer and accelerometers are used for the EMA whereas simulation is performed using ANSYS software. A $3 \mathrm{~cm} \times 3 \mathrm{~cm} \times 3 \mathrm{~cm}$ cube of dam concrete material is extracted as a sample for the initial validation process.

\section{Modelling of the Sector Gate Section of the Dam Structure}

Sector gate section is located at the center of the overall dam. In sector gate section, the release of water at the spillway location is controlled by two gates, which is sector gate and radial gate. The three-dimensional (3D) model of the sector gate section is constructed using SolidWorks software. Figure 1 shows the real and 3D model of the sector gate section which consists of several important parts.

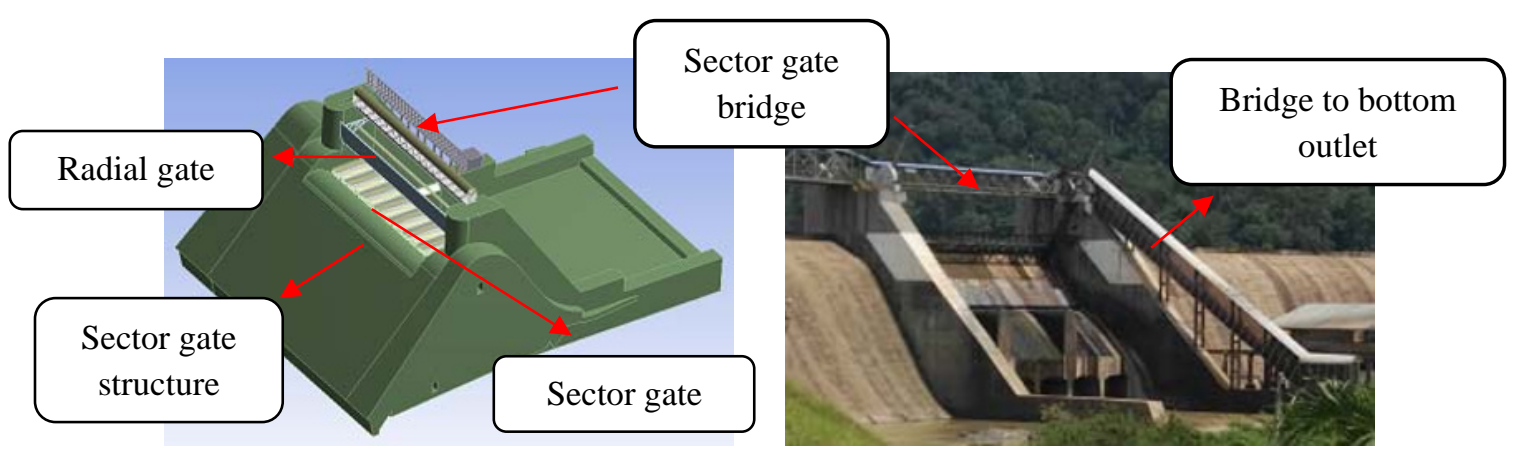

Figure 1: 3D model of sector gate section (left) and real picture of sector gate (right)

\section{FE Model and Sensitivity Analysis}

FE model of the sector gate section is developed using ANSYS software and it is made up of 433,404 tetrahedral elements. Sensitivity analysis is performed to obtain the optimized meshing type for the simulation. Three types of meshing which are hex dominant, tetrahedral and automatic mesh is investigated with the same body sizing. The boundary condition is set as fixed support for all the bottom faces. Figure 2 shows the FE model of the sector gate as well as its boundary condition. 

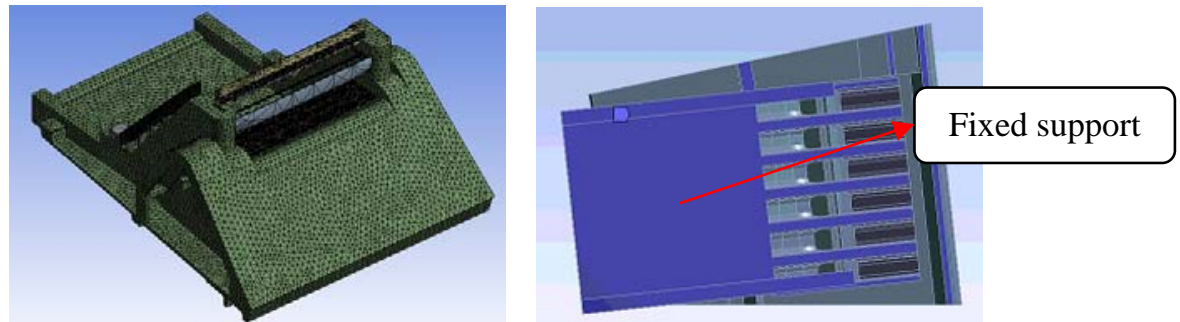

Figure 2: FE model of sector gate (left) and boundary condition (right)

\section{Modal Analysis of the Sector Gate Section}

Modal analysis of the sector gate section is performed in ANSYS software by importing the CAD file from SolidWorks software. Then, the required materials which are mild steel and concrete are added and assigned to respective parts in the sector gate section. Before starting the meshing process, all parts must share the same topology. 30 mode shapes are set as the maximum mode shapes to be determined in the this analysis.

\section{RESULTS AND DISCUSSION}

\section{Initial Validation of Dam Material}

The first natural frequency from the EMA of real dam concrete material is $6,570 \mathrm{~Hz}$ whereas simulation result gives the value of $6,400 \mathrm{~Hz}$ as the first natural frequency. By comparison, the percentage error between EMA and simulation is $2.59 \%$, which is valid for further analysis of the dam structure.

\section{Sensitivity Analysis of the Sector Gate Section}

The result of the sensitivity analysis shows that the hex dominant and tetrahedral mesh give the same first natural frequency which is $4.65 \mathrm{~Hz}$ compared to the automatic mesh which is at $4.72 \mathrm{~Hz}$ for the case of full concrete materials. Figure 3 shows the relationship between the natural frequency and types of mesh and it can be concluded that the hex dominant mesh is the optimized meshing type for the simulation.

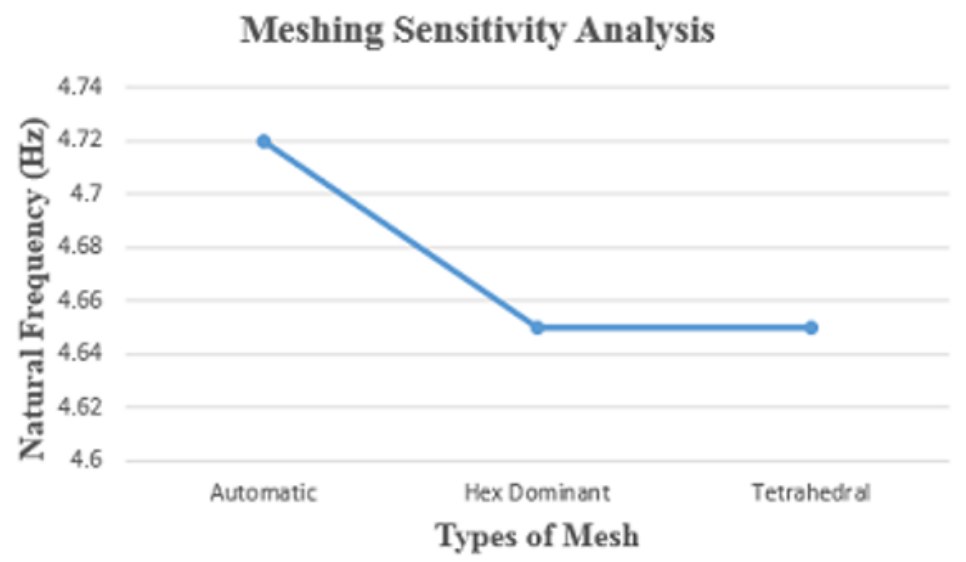

Figure 3: Sensitivity analysis of three different types of mesh (Full concrete) 


\section{Natural Frequency, Mode Shape and FRF of the Sector Gate Section}

Table 1 shows 4 out of 30 mode shapes obtained along with its corresponding natural frequencies and deflection values. It can be observed that the $16^{\text {th }}$ mode shape gives the most significant effect to the sector gate with the deflection value of $0.694 \mathrm{~mm}$ and natural frequency of $5.090 \mathrm{~Hz}$. Any vibration near to this frequency will cause deflection to the sector and radial gate, sector gate bridge, upper section of the sector gate structure and the highest deflection will occur at the bridge to the bottom outlet. From the FRF graph of harmonic analysis, the highest natural frequency of the $x, y$ and $z$ directions occurred at $7.95 \mathrm{~Hz}$ with a maximum deflection of $2.03 \times 10^{-7} \mathrm{~m}, 2 \times 10^{-7} \mathrm{~m}$ and $1.79 \times 10^{-7} \mathrm{~m}$, respectively. The highest deflection occurred at $x$ axis direction for the sector gate section. Table 2 shows all three FRF graph in $x, y$ and $z$ directions.

Table 1: First and three most significant mode shapes with its respective natural frequencies and deflection values

\begin{tabular}{|c|c|c|c|}
\hline $\begin{array}{c}\text { Modes } \\
\text { No. }\end{array}$ & Mode Shapes & $\begin{array}{c}\text { Natural } \\
\text { Frequency }\end{array}$ & $\begin{array}{c}\text { Deflection } \\
\text { Values }\end{array}$ \\
\hline 1 & & $0.5904 \mathrm{~Hz}$ & $28.41 \mathrm{~mm}$ \\
\hline 7 & & $1.908 \mathrm{~Hz}$ & $2.79 \mathrm{~mm}$ \\
\hline 16 & & $5.090 \mathrm{~Hz}$ & $0.694 \mathrm{~mm}$ \\
\hline
\end{tabular}




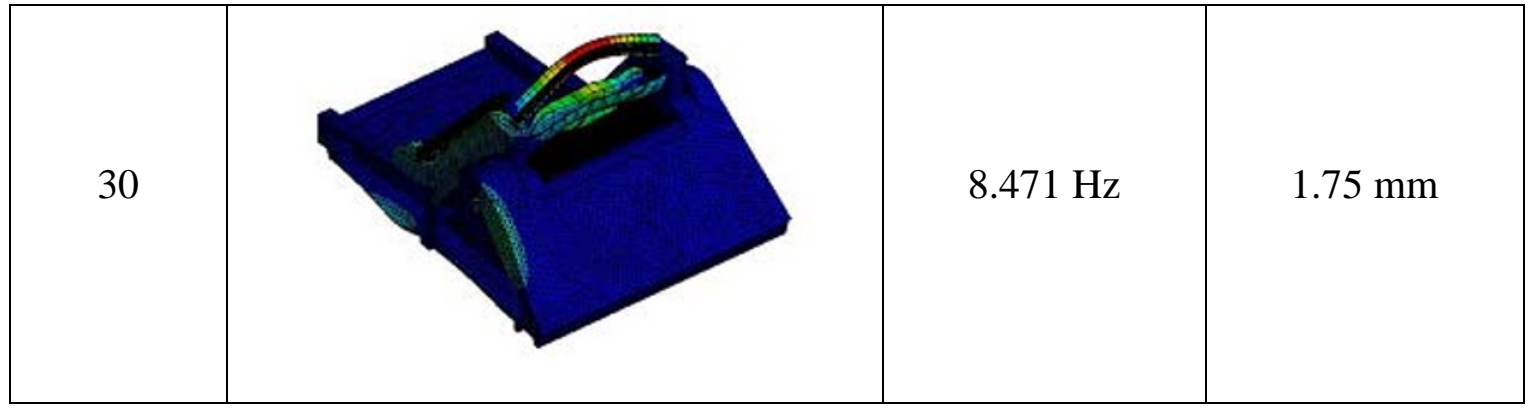

Table 2: FRF graphs for the sector gate section in $x, y$ and $z$ directions

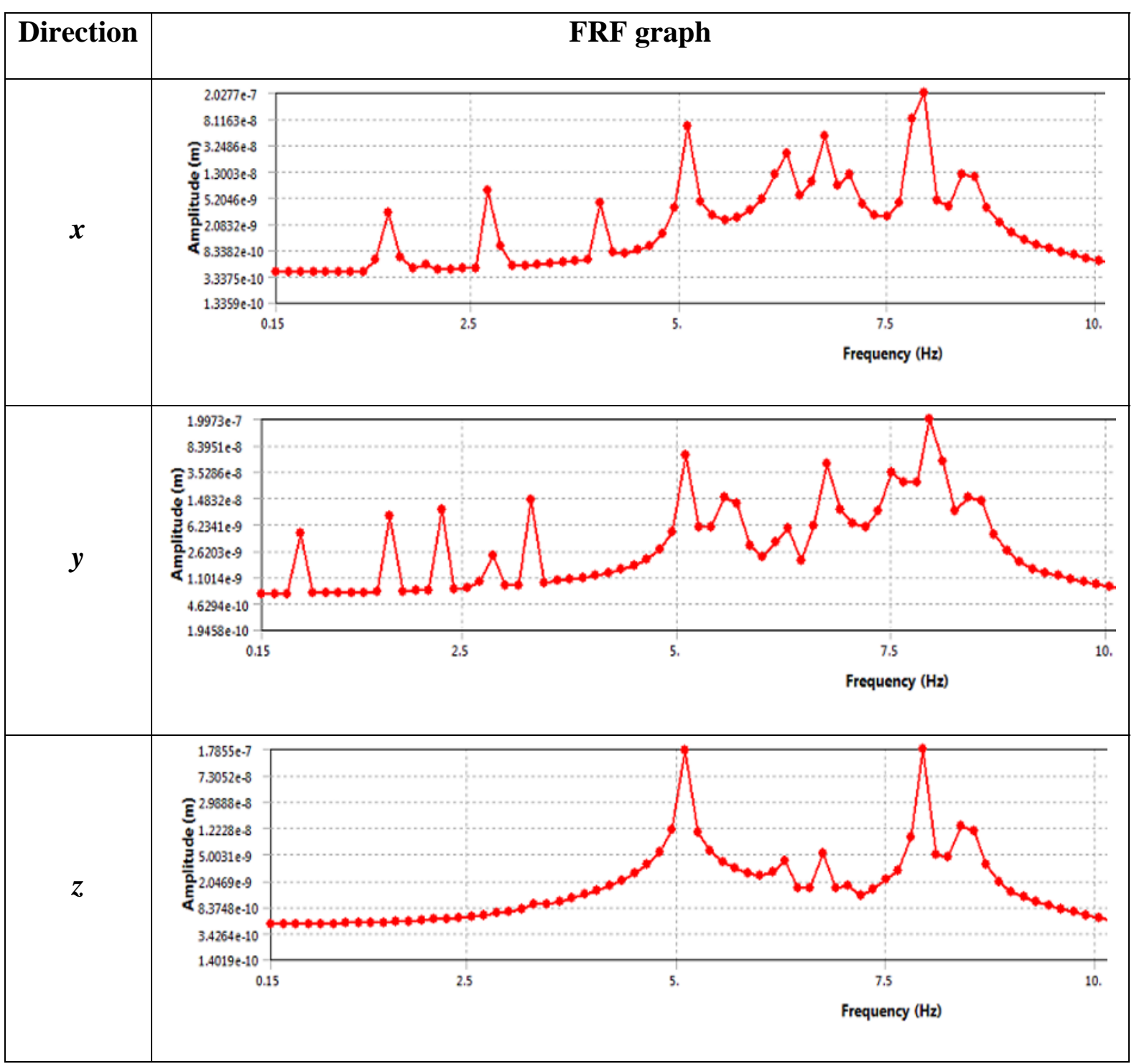

\section{CONCLUSION}

From this study, structural dynamic analysis of the Chenderoh Dam Sector Gate Section has been successfully carried out. It can be concluded that: 
- The development of the 3D model of the sector gate section has been successfully done.

- The meshing sensitivity analysis has been conducted to determine the optimum and reliable meshing for the sector gate and the hex dominant meshing is selected as the most optimum meshing.

- The modal analysis result of the sector gate section which include the natural frequencies and mode shapes have been successfully achieved with the $16^{\text {th }}$ mode shape at $5.09 \mathrm{~Hz}$ gives the most significant effect to the overall sector gate section.

- The harmonic response analysis result of the sector gate section with the FRF graph has been successfully achieved with the maximum deflection occur in $x$ direction at 7.95 $\mathrm{Hz}$.

\section{ACKNOWLEDGEMENTS}

The authors would like to acknowledge Universiti Sains Malaysia and Uniten R\&D Sdn. Bhd. for providing the facilities and financial assistance under accounts (304/PMEKANIK/60313052 and U-841).

\section{REFERENCES}

[1] Vezi M. (2014). Dynamic Modelling of Arch Dams in the Ambient State. Doctoral Dissertation, University of Cape Town.

[2] Chapter 3: Real Eigenvalue Analysis (2005). Retrieved from: http://www2.me.rochester.edu/courses/ME443/NASTRAN/Chpt3RealEigenvalue Analysis.pdf.

[3] Chapter 10: Harmonic Analysis. (2005). ANSYS Training Manual. Inventory \#00221510-4.

[4] C. M. Ramesha, Abhijith K. G., Abhinav Singh, Abhishek Raj and Chetan S Naik. (2015). Modal Analysis and Harmonic Response Analysis of a Crankshaft. International Journal of Emerging Technology and Advanced Engineering, Volume 5 , Issue 6.

[5] Shanshan W. and Qingwen Ren. (2011). Dynamic Response of Gravity Dam Model with Crack and Damage Detection. Science China Technological Sciences, 54(3), 541-546. 